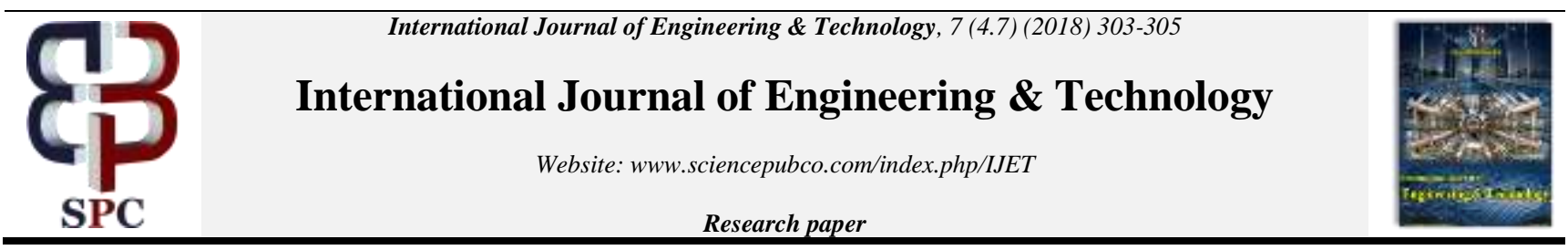

\title{
An Experimental Investigation on Nano Coast as Bearing Liners
}

\author{
K.S.K. Mallik ${ }^{1 *}$, Dr. K.V. Ramana ${ }^{2}$ \\ ${ }^{1}$ Research scholar, Department of Mechanical Engineering. Koneru Lakshmaiah Educational Foundation, Vaddeswaram, Guntur, An- \\ dhra Pradesh, India \\ ${ }^{2}$ Professor, Department of Mechanical Engineering. Koneru Lakshmaiah Educational Foundation, Vaddeswaram, Guntur, Andhra Pra- \\ desh, India \\ *Corresponding author E-mail: kskmallik@gmail.com
}

\begin{abstract}
Liners which are integral part of journal bearings, have a significant role on the life of a bearing. These are typically in the form of a bush, sleeve or a loop. Enhanced performance of a bearing liner with less cost is always acceptable. Coatings are the most preferable alternate for the existing bearing liners. Babbitt alloy is the one which is commonly used as bearing bush material. Tin, which is the significant material in the Babbitt is costly. In this work an experimental investigation has been taken-up by replacing Tin with Cadmium having similar mechanical and thermal properties as that of Tin but at the same time very less in cost. A nano coat of the alloy consisting of Antimony, Copper, Lead and Cadmium has been given on a mild steel specimen and experimented for Surface roughness and Hardness. The results are compared with Babbitt.
\end{abstract}

Keywords: Bearing liner, Babbitt,Ball milling, Nano coating, Hardness, Surface roughness.

\section{Introduction}

Babbitt metal is an antifriction metal alloy first developed by Isaac Babbitt in 1839 showed excellent bearing properties compared to other liner materials. Babbitt offers an almost unsurpassed combination of compatibility, conformability and embedability.The main properties any bearing liner should possess are Hardness, Bearing Strength, and fatigue strength. Bearing liner displacement and material loss are common problem face by a liner which affects the relative motion between the surfaces and lead to bearing failure. Cycle A. Branaganetal [1] in their survey taken up the sources and consequences of damage to industrial bearings which operate by means of hydro dynamic or hydrostatic lubrication. K.M.Bhuptanietal [2] has investigated friction and wear behavior analysis of different journal bearing liner materials. They have studied the tribological behavior of conventional materials such as Brass and Gun metal. S.B. Chikalthankaretal [3] in their work, discussed the general requirements, properties causes of failure and their remedies of bearing materials. Coatings had become an alternative solution for many problems now-a-days. Nano composite coatings have a major advantage of addition of properties than normal coatings. A top down approach, ball milling method [4] is most commonly used and an effective method to obtain nano particles.Spraying, Sol-gel, and Spin coating are generally used coating techniques. M.J. Azizpouretal [5] compared thermal spraying method and casting and explained the better performance and tribological behavior of thermally sprayed Babbitt layer. M.Kasparovaetal [6] have evaluated the friction properties of externally sprayed Nano-Coats of tin based Babbitt. Sunil Mohan etal [7] observed that tribological properties can be enhanced by coatings. A.Voevodinetal [8] has concluded that nano coatings improved tribological responses.Sotomi Ishihara etal [9] had investigated the wear resistance of white metal. M. Ozgur boraetal [10] has studied the tribological behavior of different tin based bearing materials for their hardness. SamZhangetal [11] in their reviewobserved that much attention is to be paid to increase the hardness but not toughness. V.V. Ilyushinetal [12] have studied variations in tribological characteristics such as friction coefficient and wear rate using different methods and have conducted a micro structural metallographic analysis. N.V.Koberniketal [13] has studied the friction and wear rate of Babbitt alloy coatings modified with carbon nanotubes as fillers. B.S.Unluetal [14] in their work have determined the tribological properties of white metal. K. V. Ramanaetal [15] investigated the mechanical properties like hardness and bearing stress of nano composite coating and observed good results when compared with general bearing liner materials.

\section{Methodology}

Antimony, copper, lead and cadmium, the basic constituent metals of the proposed composite are purchased in micro size from LOBA CHEMIE Pvt Ltd and ALDRICH Pvt Ltd.

\subsection{Ball Milling method}

The top down approach of getting nano particles using ball milling is carried out on Insmart systems ball milling equipmentas shown in Fig. 1. 


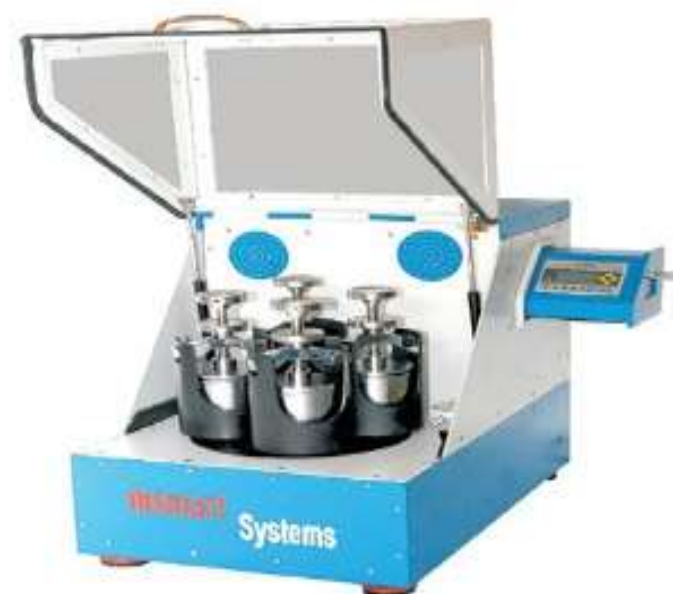

Figure 1:. Insmart systems planetary ball milling equipment

The vials and balls are made of tungsten carbide. The specifications considered for the process are as mentioned. Ball powder ratio of 5:1; Balls of weight $6 \mathrm{~mm}$ and $10 \mathrm{~mm}$ diameters are 2 grams and 8grams respectively. The RPM considered is 350. On-time and off-time are $4 \mathrm{~min}$ and $1 \mathrm{~min}$ respectively. No of cycles are 12 . Total run time obtained as

Total run time: No of cycles*(on time + off time) min i.e. $12 *(4+1)=60 \mathrm{~min}$.

The total time (in hrs) required for each individual material for obtaining nano size are $41,52,56$, and 49 for antimony, copper, lead, and cadmium respectively. The nano size of the ball milled metal powders are confirmed through Bruker's X-Ray Diffraction, and through Scherrer equation, $\mathrm{D}=\mathrm{k}^{\prime} \lambda^{\prime} /\left(\beta^{\prime} * \cos \theta\right)$. The obtained nano size of the particle is $10 \mathrm{~nm}$. The milling process has been presented in Fig. 2.

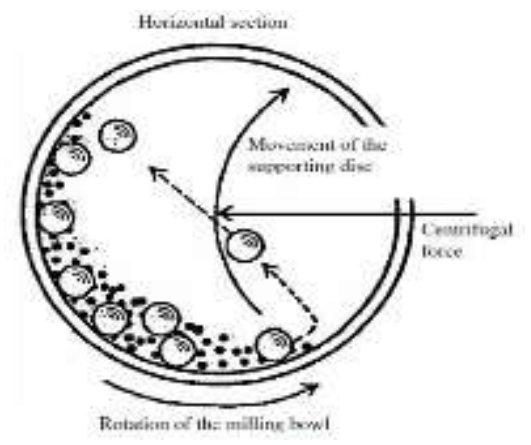

Figure 2: Ball milling process

\subsection{Sol-Gel Spin Coating Technique}

The nano powders of the materials are weighed and mixed in required compositions to obtain the nano composite powder. The four compositions considered are shown below.

Table 1: Compositions considered

\begin{tabular}{|c|c|c|c|c|}
\hline Composition & $\mathrm{Cd} \%$ & $\mathrm{~Pb} \%$ & $\mathrm{Sb} \%$ & $\mathrm{Cu} \%$ \\
\hline $\mathrm{A}$ & 95 & 3 & 1 & 1 \\
\hline $\mathrm{B}$ & 97 & 1 & 1 & 1 \\
\hline $\mathrm{C}$ & 3 & 89 & 5 & 3 \\
\hline $\mathrm{D}$ & 1 & 95 & 3 & 1 \\
\hline
\end{tabular}

A solution is prepared with $1 \mathrm{gm}$ of required nano composite powder, $5 \mathrm{ml}$ of ethanol (as solvent). A $10 \%$ in solution, that is $0.5 \mathrm{mg}$ of PVP (as epoxy) is added to the solution so as to obtain required viscosity. The solution is stirred using a magnetic stirrer at room temperature for about 18-24 hrs. A mild steel piece as substrate of $2 \mathrm{~mm}$ thickness is cleaned with acetone and heated about 15 20 mins in hot air oven at $200^{\circ} \mathrm{C}$ to remove the impurities. After preparing the solution, nano coatings are obtained by applying the solution drop by drop on the mild steel substrate using spin coating equipment shown in Figure 3. The requirements of spin coating technique, time and speed for each nano coating are mentioned in Table 2. The substrates are again dried in hot air oven at $200^{\circ} \mathrm{C}$ for 15-20mins for annealing of coatings. The mild steel pieces coated with four different coatings are tested under Olympus GX71 inverted metallurgical microscope as shown in Fig. 3 with 2000X magnification. The coating thickness varies from specimen to specimen and the average coating thickness is 60 microns.

Table 2: Specifications of spin coating technique

\begin{tabular}{|c|c|c|}
\hline Composition & Spin speed (rpm) & Spin time $(\mathrm{sec})$ \\
\hline A & 1500 & 30 \\
\hline B & 1500 & 30 \\
\hline C & 1500 & 30 \\
\hline D & 1500 & 30 \\
\hline
\end{tabular}

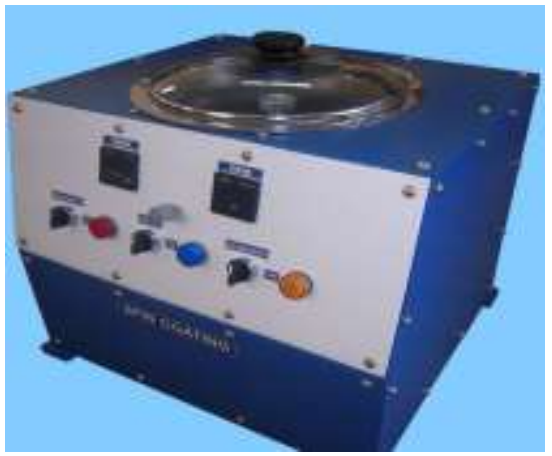

Figure 3:. Spin coating equipment

\section{Experimental Study}

\subsection{Surface Roughness}

The surface roughness of the coating is tested through TAYLOR HOBSON Surtronic S128 surface roughness testing equipment as given in Fig. 4. Surface roughness test is conducted in three different directions on the specimen and the mean value is calculated.

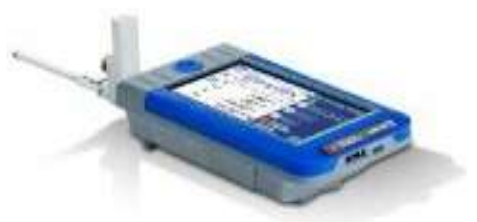

Fig 4:. TAYLOR HOBSON Surtronic S128 surface roughness tester

\subsection{Hardness}

The hardness of the specimens is tested through Universal hardness tester as shown in Fig 5. Brinell's hardness number is calculated by $h_{b}=2 F /\left[\pi D(D-\sqrt{(D-d)})\right.$ where $h_{b}=$ hardness number, $F$ is load of $3000 \mathrm{kgf}, \mathrm{D}$ is the diameter of indenter $(10 \mathrm{~mm})$ and $\mathrm{d}$ is diameter of indentation. The hardness test is conducted at three different points in three different directions on the specimen and the mean value is arrived at. 


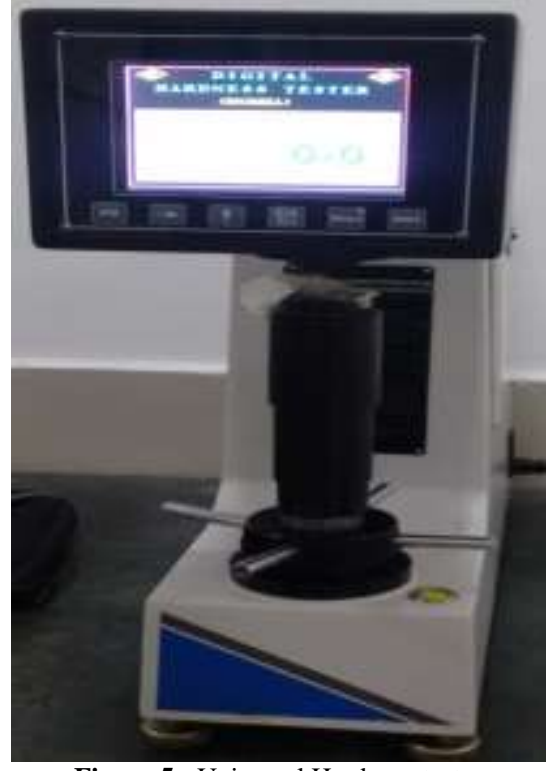

Figure 5:. Universal Hardness tester

\section{Results}

The results obtained through experimental study are tabulated along with graphical representation.

\subsection{Surface Roughness}

Surface roughness values are presented in Table. 3

Table 3:. Surface roughness values

\begin{tabular}{|c|c|c|c|c|}
\hline S. No & Cd95\% & Cd97\% & Pb89\% & Pb95\% \\
\hline 1 & 0.8 & 1.6 & 2.0 & 2.4 \\
\hline 2 & 0.8 & 1.6 & 1.9 & 2.0 \\
\hline 3 & 0.7 & 1.5 & 1.8 & 2.5 \\
\hline Mean & 0.76 & 1.56 & 1.9 & 2.3 \\
\hline $\begin{array}{c}\text { Babbitt } \\
\text { alloy }\end{array}$ & \multicolumn{5}{|c|}{2.33} \\
\hline
\end{tabular}

Fig. 6 shows the variation of surface roughness with respect to percentage composition

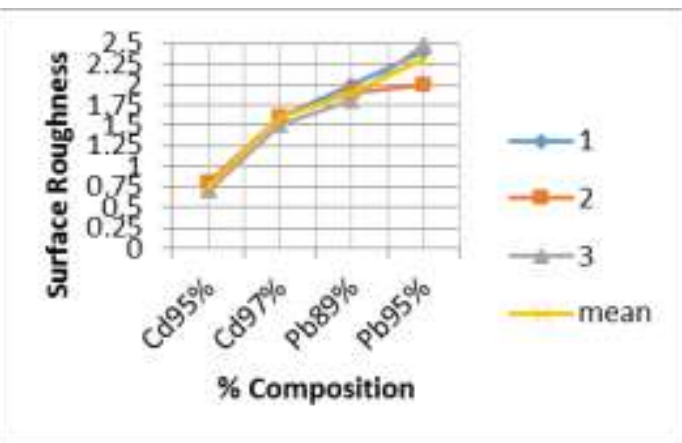

Fig 6:. Percentage Composition vs Surface roughness

\subsection{Hardness}

Surface hardness values are presented in Table 4

Table 4. Surface Hardness values

\begin{tabular}{|c|c|c|c|c|}
\hline S.No & Cd95\% & Cd97\% & Pb89\% & Pb95\% \\
\hline 1 & 172 & 141 & 146 & 111 \\
\hline 2 & 146 & 132 & 132 & 125 \\
\hline 3 & 138 & 136 & 136 & 135 \\
\hline Mean & 152 & 136 & 138 & 123 \\
\hline $\begin{array}{c}\text { Babbitt } \\
\text { alloy }\end{array}$ & \multicolumn{5}{|c|}{30} \\
\hline
\end{tabular}

Fig. 7 shows the variation of surface roughness with respect to percentage composition

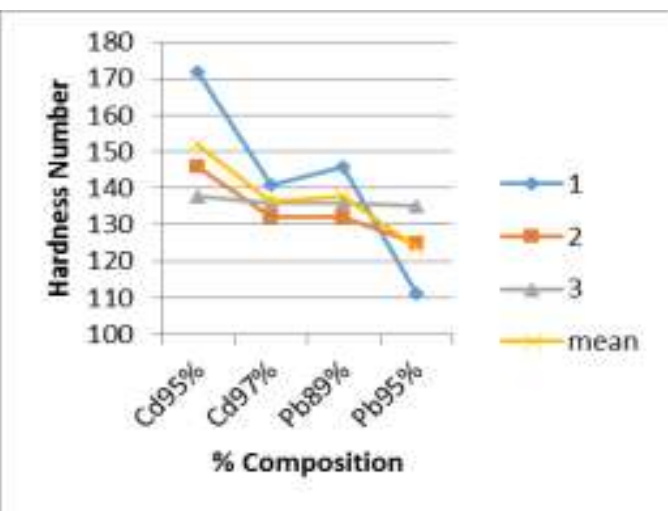

Fig 7:. Percentage composition vs Hardness number

\section{Conclusion}

1. The surface roughness of the coating with Cd95\% is 0.76 which is much better compared to Babbitt which is 2.33 .

2. The hardness number of Cd95\% coating is 152 which makes this coating a much preferable as an alternate for Babbitt liner whose Hardness number is 30 .

It can be concluded that $\mathrm{Cd} 95 \%$ exhibits better properties when compared to other coatings and also Babbitt liner.

\section{References}

[1] Lyle. A. Brangan, Resistance of white metals survey damage of Babbitt industriesbearing, Lubricants, 3, 2015, 91-112

[2] M. Bhupatnani, Friction and wear behavior analysis of different journal bearing materials,

[3] International Journal of Engineering Research \& Technology, 3(4), 2013, 2141-2146

[4] S.B. Chikalthankar, Comparative study of bearing materials and failure of plain bearings. International Journal of Engineering Research \& Technology, 2(3), 2014, 2402-2406]

[5] T.P. Yadav, Mechanical milling: A top down approach for the synthesis of nano materials and nano composites, Nano Science and Nano Technology, 2(3), 2012, 22-48

[6] M.J. Azizpour, Babbitt casting and Babbitt spraying processes, International Journal of Mechanical, Aerospace, Industrial, Mechantronic and Manufacturing Engineering, 5(8), 2011

[7] M. Kasporava, Evaluation of the fiction properties of thermally sprayed coatings,

[8] Tribology and design, 66, 2010, 117-127

[9] Sunil Mohan, Wear friction and prevention of tribosurfaces by Nano coatings, Anti

[10] Abrasive nano coatings, 2015, 003-022

[11] A. Voevodin, Recent advances of hard tough low friction of NC coatings, Materials and

[12] Manufacturing directory, 10(6), 2005, 665-679

[13] S. Ishihara, Effect of amount of antimony on sliding wear resistance of white metal,

[14] Tribology and Design,43(5-6), 2010, 935-938

[15] M. Özgür bora, Instrumented indentation and scratch testing evaluation of tribologicalproperties of tin based bearing materials, Material and design, 31(6), 2010, 2707-2715

[16] Sam zhang, Recent advances of super hard Nano-composites, Surface coating andtechnology, 67(2-3), 2003, 113-119

[17] V.V. Ilyyushin, Effect of production methods of tribological characteristics of Babbitt coatings, Friction and wear, 33(3), 2012, 190-194

[18] N.V. kobernik, Triobological properties of Babbitt alloy coatings modifies with carbonnanotubes, Inorganic materials and applied research, 8(3), 2017, 428-433

[19] B.S. Unlu, Determination of the tribological and mechanical properties of $\mathrm{SnPbCuSb}$ (white metal) bearings, Material Science, 46(4), 2011, 4752

[20] K.V. Ramana, Nano coatings as a bearing liner - An experimental investigation, International Journal of Mechanical engineering and Technology, 5(9), 2018, 58-63 